\title{
Identification of neutral genes at pollen sterility loci $S d$ and $S e$ of cultivated rice (Oryza sativa) with wild rice $(O$. rufipogon) origin
}

\author{
B. Liu, J.Q. Li, X.D. Liu, M.Q. Shahid, L.G. Shi and Y.G. Lu \\ State Key Laboratory for Conservation and Utilization of Subtropical \\ Agro-Bioresources, College of Agriculture, \\ South China Agricultural University, Guangzhou, China \\ Corresponding authors: J.Q. Li / Y.G. Lu \\ E-mail: lijinquan@scau.edu.cn / yglu@scau.edu.cn
}

Genet. Mol. Res. 10 (4): 3435-3445 (2011)

Received April 19, 2011

Accepted September 8, 2011

Published October 31, 2011

DOI http://dx.doi.org/10.4238/2011.October.31.10

\begin{abstract}
Pollen sterility is one of the main hindrances against the utilization of strong intersubspecific (indica-japonica) heterosis in rice. We looked for neutral alleles at known pollen sterility loci $S d$ and $S e$ that could overcome this pollen sterility characteristic. Taichung 65, a typical japonica cultivar, and its near isogenic lines E7 and E8 for pollen sterility loci $S d$ and $S e$ were employed as tester lines for crossing with 13 accessions of wild rice (O. rufipogon). Pollen fertility and genotypic segregations of the molecular markers tightly linked with $S d$ and $\mathrm{Se}$ loci were analyzed in the paired $\mathrm{F}_{1} \mathrm{~s}$ and $\mathrm{F}_{2}$ populations. One accession of wild rice (GZW054) had high pollen fertility in the paired $\mathrm{F}_{1} \mathrm{~s}$ between Taichung 65 and E7 or E8. Genotypic segregations of the molecular markers tightly linked with $S d$ and $S e$ loci fit the expected Mendelian ratio (1:2:1), and non-significances were shown among the mean pollen fertilities with the maternal, parental, and heterozygous genotypes of each molecular markers tightly linked with $\mathrm{Sd}$ and $\mathrm{Se}$ loci. Evidentially, it indicated that the alleles of $S d$ and $S e$ loci for GZW054 did not interact with those of Taichung 65 and its near isogenic lines, and, thus were identified as neutral alleles $S d^{n}$ and $S e^{n}$. These neutral
\end{abstract}


genes could become important germplasm resources for overcoming pollen sterility in indica-japonica hybrids, making utilization of strong heterosis in such hybrids viable.

Key words: Rice (Oryza sativa); Wild rice (Oryza rufipogon); Pollen sterility; Neutral gene; Molecular marker

\section{INTRODUCTION}

Asian cultivated rice (Oryza sativa L.) can be classified into two distinct subspecies i.e., indica and japonica (Kato, 1930). Inter-subspecific hybrids have significant hybrid vigour that provides greater increase in rice production (Yuan, 1987). However, the partial or complete hybrid sterility hinders the utilization of strong heterosis between subspecies (Long et al., 2008).

The mechanism of $F_{1}$ sterility in subspecies is complex. There are different theories about the hybrid sterility in rice, such as male gamete abortions (Zhang et al., 1993; Liu et al., 2004), female gamete abortions (Yokoo, 1984; Liu et al., 2004) and reduced dehiscence of anthers (Zhang et al., 2006). Among them, pollen and embryo sac sterility are the two most important factors which cause hybrid sterility and both of them have contributed almost equally to spikelet fertility (Song et al., 2005). Wide compatibility and specific compatibility hypothesis are the main theories for rice hybrid sterility. The former theory concerns female gamete abortion (embryo sac sterility) and it is caused by an allelic interaction $\left(S 5^{i}, S 5^{j}\right.$ and $\left.S 5^{n}\right)$ at $S_{5}$ locus on chromosome 6 as well as other loci with minor effects including $S-7, S-8, S-9$, $f 1, f 3, f 8, S_{d 1}{ }^{n}(t), S_{d 2}{ }^{n}(t)$ and $S-p(t)$ (Wan and Ikehashi, 1997; Yi et al., 2001). $S_{5}$ locus has been successfully cloned (Chen et al. 2008). The latter one concerns male gamete abortion (pollen sterility) and controlled by at least six loci (i.e., $S a, S b, S c, S d$, $S e$ and $S f$ ) (Zhang and Lu, 1989, 1993). Until now, the $S a$ gene has been successfully cloned and two adjacently located genes ( $\mathrm{SaM}$ and $\mathrm{SaF}$ ) jointly controlled indica-japonica hybrids sterility. Typical japonica cultivars contain $\mathrm{SaM}^{-} \mathrm{SaF}^{-}$and typical indica cultivars contain $\mathrm{SaM}^{+} \mathrm{SaF}^{+}$alleles at this locus, and the interaction between $\mathrm{SaM}^{+} / \mathrm{SaM}^{-}$lead to abortion of the male gametes carrying the $\mathrm{SaM}^{-}$allele in the presence of $S a F^{+}$allele (Long et al., 2008). The $S b, S c$, and $S d$ loci have been finely mapped (Yang et al., 2004; Li et al., 2006; Li et al., 2008), and Se locus has been preliminary targeted (Zhu et al., 2008).

Gene interaction at each pollen sterility locus could lead to partly abortive pollen. Therefore, the alleles that do not interact with typical japonica $\left(S^{\prime}\right)$ and indica $\left(S^{i}\right)$ alleles called neutral alleles for pollen fertility $\left(S^{n}\right)$ and they have significant importance to overcome the pollen sterility caused by each locus (Shi et al., 2009). A few neutral genes for certain pollen sterility loci were identified in cultivated rice (Ding et al., 2003). O. rufipogon Griff. Is the ancestor of cultivated rice and has great genetic diversity and elite genes for rice breeding. $O$. rufipogon covers a large area in Gaozhou, Guangdong province. Earlier studies in our laboratory indicated that they might have neutral genes for pollen fertility in wild rice (Li et al., 2007; Lian et al., 2008). Using Taichung 65 and its near-isogenic line (NIL) at $S b$ locus as tester lines an accession of $O$. rufipogon GZW099 was identified to have the neutral gene for pollen fertility at $S b$ locus (Shi et al., 2009). Sd and $S e$ loci have important effect on pollen fertility in $\mathrm{F}_{1}$ between indica and japonica (Li et al., 2008; Zhu et al., 2008). However, no neutral genes at $S d$ and $S e$ 
loci have been identified either in cultivated rice or in wild rice.

An NIL of Taichung 65 (i.e., E7) for $S d$ locus was bred by successive backcrossing and molecular assistant selection, using the japonica variety Taichung 65 (E1) as recipient parent and the indica variety Dee-geowoo-gen as donor parents (Li et al., 2003, 2008). Another NIL of Taichung 65 (i.e. E8) at $\mathrm{Se}$ locus was also bred by the similar manner, which is the $\mathrm{BC}_{4} \mathrm{~F}_{3}$ of Taichung 65 (recurrent parent) and the indica variety Guangluai-4 (donor parent) (Zhu et al., 2008). Taichung 65 and its NILs at $S d$ and $S e$ loci (i.e. E7 and E8) have a similar genetic background except some genotypic differentiation at $S d$ and $S e$ locus, i.e. genotypes $S_{d}^{j} S_{d}^{j}$, $S_{e}^{j} S_{e}^{j}$ for E1, $S_{d}^{i} S_{d}^{i}, S_{e}^{j} S_{e}^{j}$ for E7 and $S_{d}^{j} S_{d}^{j}, S_{e}^{i} S_{e}^{i}$ for E8. The model of gene interaction for $S d$ and $S e$ locus fitted the one-locus sporo-gametophytic interaction model (Zhang and Lu, 1989, 1993). That is to say, indica and japonica varieties usually possess $S^{i} S^{i}$ and $S^{S} S^{i}$ alleles, respectively, at a locus, and the gametes having $S^{j}$ allele are partially aborted in the hybrid genotype $S^{i} S$.

To explore the neutral gene for pollen fertility at the $S d$ and $S e$ loci in Gaozhou wild rice, Taichung 65 and its NIL E7 and E8 were used as the genetic testers in this study. Thirteen accessions of Gaozhou wild rice were selected to cross with the genetic testers. Analyses were made on pollen fertility of $\mathrm{F}_{1}$ and $\mathrm{F}_{2}$ within the pairs of testcross and the genotypic segregation of the molecular markers linked tightly with these two loci to identify the neutral allele. The objective of the present study was to identify the neutral genes for pollen fertility in $O$. rufipogon at $S d$ and $S e$ locus and offer new germplasms for overcoming the pollen sterility in indica-japonica hybrids.

\section{MATERIAL AND METHODS}

\section{Plant materials}

Taichung $65\left(S_{d}^{j} S_{d}^{j}, S_{e}^{j} S_{e}^{j}\right)$, E7 $\left(S_{d}^{i} S_{d}^{i}\right)$ and E8 $\left(S_{e}^{i} S_{e}^{i}\right)$ were used as female parents, which have same genetic background except at $S d$ and $S e$ locus and was kindly provided by professor Zhang GuiQuan. O. rufipogon indigenous to Gaozhou, Guangdong province which is conserved at the Oryza genus germplasm resources of South China Agricultural University (SCAU), was used as the male parent. A total of 13 accessions of wild rice from Gaozhou (GZW) were selected: GZW006, GZW009, GZW011, GZW013, GZW026, GZW054, GZW060, GZW099, GZW101, GZW133, GZW135, GZW136, and GZW137 from 6 populations of 141 accessions. Crosses were made at SCAU from 2006 to 2007. The $\mathrm{F}_{1}$ plants were sown at the same time in late season, 2007 at SCAU. The $\mathrm{F}_{2}$ plants derived from $\mathrm{F}_{1}$ were sown in late season, 2007 at Sanya, Hainan province.

\section{Pollen fertility analysis}

Five spikelets that would open the following day in the top area of each spike of main tiller were selected and fixed into Carnoy's fixative solution for $24 \mathrm{~h}$. Then they were transferred to $70 \%$ alcohol. Three spikelets were selected randomly and dissected. Pollen grains were stained with $1 \%$ iodine potassium iodide $\left(\mathrm{I}_{2}-\mathrm{KI}\right)$ solution. Microscopic observation of pollen was done under Motic BA200 at $10 \times 20$. More than 300 pollen grains were scanned randomly on each slide and pollen fertility was divided into four categories i.e., normal pollens, stained abortive pollens, spherical abortive pollens and typical abortive pollens (Shahid et al., 2010). 


\section{DNA extraction and SSR analysis}

The genomic DNA was extracted from fresh-frozen leaves of each plant as described by Zheng et al. (1995) with minor modifications.

We selected 5 and 4 polymorphic pair of SSR primers based on the fine mapping of $S d$ and $S e$ locus, and these primers were linked tightly with $S d$ and $S e$ locus, respectively. The genetic distance of PSM13, PSM91, PSM41, PSM42, and PSM43 from Sd locus was 0.4, $0.05,4.8,4.8$ and $3.2 \mathrm{cM}$, respectively. The distance of PSM597, PSM448, and PSM461 from $\mathrm{Se}$ locus was 4.75, 0.2 and $0.6 \mathrm{cM}$, respectively. PSM559 was inside the $\mathrm{Se}$ locus. PSM597 and PSM559 are InDel markers, whereas the others are SSR markers. PCR and genotyping were done according to Shi et al. (2009).

\section{Identification method for the neutral gene at $S d$ and $S e$ loci}

Identification method for the neutral genes $S d$ and $S e$ loci was modified from the method of Shi et al. (2009). The genotype of candidate tested line was assumed to be $S_{d}^{x} S_{d}^{x}$. Firstly, the candidate tested line was crossed with both E1 and E7 (when $S d$ locus was detected; or E8 when Se locus was detected) to make a pair of test combinations. Because E1 and E7 (or E8) had the same genetic background and differed only at $S d$ (or $\mathrm{Se}$ ) locus, the significant difference of pollen fertility in the same pair of test combination was due to the allelic interaction at $S d$ (or $S e$ ) locus and the allelic interactions at the other loci were the same. Thus the influence of the genetic background was reduced. The interaction of the testcross at $S d$ (or $\mathrm{Se}$ ) locus would be one of following three conditions.

If $S_{d}^{x} S_{d}^{x}$ is $S_{d}^{i} S_{d}^{i}$, the genotype of the $\mathrm{F}_{1}$ from the testcross between the candidate tested line and E1 should be $S_{d}^{i} S_{d}^{j}$. F pollen and the gametes of $S^{j}$ would be partly abortive because of the allelic interaction. Correspondingly, the genotypes of molecular markers tightly linked with $S d$ locus in $\mathrm{F}_{2}$ generation would show a deviated distribution with reduced numbers of the alleles from E1 ( $S_{d}^{i}$ gamete). However, the genotype of the $\mathrm{F}_{1}$ from the testcross between the candidate tested line and E7 was $S_{d}^{i} S_{d}^{i}$, and thus, the pollen fertility of $\mathrm{F}_{1}$ was normal due to no allelic interaction. The corresponding molecular marker linked with $\mathrm{Sd}$ locus in $\mathrm{F}_{2}$ population would segregate according to Mendelian ratio $(1: 2: 1)$.

If $S_{d}^{x} S_{d}^{x}$ is $S_{d}^{j} S_{d}^{j}$, the genotype of the $\mathrm{F}_{1}$ from the testcross between the candidate tested line and E1 should be $S_{d}^{j} S_{d}^{j}$ and the $\mathrm{F}_{1}$ pollen was fertile because of no allelic interaction. The corresponding molecular marker linked with $S d$ locus in its $\mathrm{F}_{2}$ population should follow the Mendelian segregation (1:2:1). However, the genotype of the $\mathrm{F}_{1}$ from the testcross between the candidate tested line and E7 should be $S_{d}^{j} S_{d}^{i}$. F pollen and the gametes of $S^{j}$ were partly abortive because of an allelic interaction. Correspondingly, the genotypes of molecular marker tightly linked with $S d$ locus in its $\mathrm{F}_{2}$ population would show deviated distribution with less numbers of the alleles from candidate tested line $\left(S_{d}^{i}\right.$ gamete).

If $S_{d}^{x} S_{d}^{x}$ is $S_{d}{ }^{n} S_{d}^{n}$, the genotype of the $\mathrm{F}_{1}$ from the testcross between the candidate tested line and E1 or E7 should be $S_{d}{ }^{n} S_{d}^{j}$ or $S_{d}{ }^{n} S_{d}^{i}$. Allele $S_{d}{ }^{n}$ was compatible with both $S_{d}^{j}$ and $S_{d}^{i}$, so there was no allelic interaction between them. The $\mathrm{F}_{1} \mathrm{~s}$ of them were fertile and would show non-significant differences between two crosses. The genetic segregation ratio of corresponding molecular marker linked with $\mathrm{Sd}$ locus in both $\mathrm{F}_{2}$ population should be in accordance with Mendelian ratio (1:2:1). 
The above method was used to identify the neutral gene for pollen fertility at $S d$ locus and same method was used to detect neutral gene at $S e$ locus.

\section{RESULTS}

\section{Preliminary selection of materials carrying neutral gene}

According to previous studies, a total of 13 wild rice accessions, which had high pollen fertility, embryo sac fertility and seed set percentage or their $F_{1} s$ when crossed with E1, were selected from 141 accessions of GZW. The average pollen fertility of $F_{1}$ s obtained from the testcrosses of GZW006, GZW099, GZW094, GZW133 with E1 was significantly higher than the corresponding $\mathrm{F}_{1} \mathrm{~s}$ between these wild rice and E7, showing that the genotype at the $S d$ locus for the four accessions of wild rice was $S_{d}^{j} S_{d}^{j}$. Similarly, average pollen fertility of E1 $\times$ GZW094 and E1 $\times$ GZW133 was significantly higher than that of E8 $\times$ GZW094 and E8 $\times$ GZW133, indicating $S_{e}^{j} S_{e}^{j}$ genotype at $S e$ locus.

Average pollen fertility for E1 $\times$ GZW054, E7 $\times$ GZW054 and E8 $\times$ GZW054 was more than $94 \%$ and their parents also showed high pollen fertility and seed set $(>90 \%)$. Non significant differences were found based on a Student's-t-test in $\mathrm{F}_{1}$ generation (Figure 1, Table 1). These results indicated that GZW054 might posses the neutral genes for pollen fertility at $S d$ and $S e$ locus and further checked by molecular markers. Similarly, average pollen fertility for E1 $\times$ GZW013 and E8 $\times$ GZW013 were high and non-significant, indicating that GZW013 might possess neutral genes at $\mathrm{Se}$ locus.

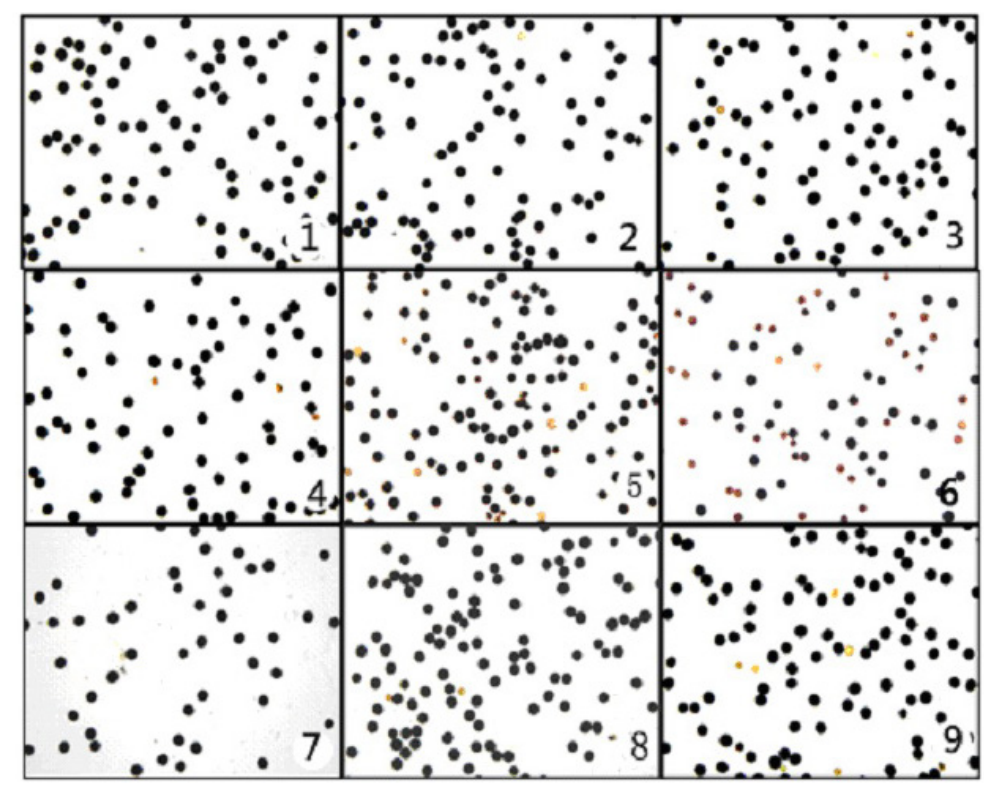

Figure 1. Pollen fertility of different genotypes in $\mathrm{E}_{1}, \mathrm{E}_{7}, \mathrm{E}_{8}, \mathrm{GZW} 054$ and their $\mathrm{F}_{1} \mathrm{~s} .1$. $\mathrm{E}_{1}$ (genotype $S_{d}^{j} S_{d}^{j}, S_{e}^{j} S_{e}^{j}$ );

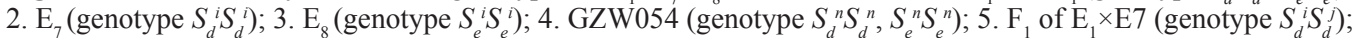
6. $\mathrm{F}_{1}$ of $\mathrm{E}_{1} \times \mathrm{E}_{8}\left(S_{e}^{i} S_{e}^{j}\right) ; 7$. $\mathrm{F}_{1}$ of E1 $\times \mathrm{GZW054}\left(\right.$ genotype $\left.S_{d}^{j} S_{d}^{n}, S_{e}^{j} S_{e}^{n}\right) ; 8$. $\mathrm{F}_{1}$ of E7 $\times$ GZW054 (genotype $\left.S_{d}^{i} S_{d}^{n}\right) ; 9$. $\mathrm{F}_{1}$ of E8×GZW054 (genotype $S_{e}^{j} S_{e}^{n}$ ). 
Table 1. Pollen fertility in $\mathrm{F}_{1} \mathrm{~s}$ between different accession of Gaozhou wild rice and Taichung 65 (E1) and its NILs (E7, E8).

\begin{tabular}{|c|c|c|c|}
\hline Testcross & Pollen fertility $(\%)($ mean \pm SE) & $t$ value & $P$ value \\
\hline E1×GZW006 & $80.64 \pm 5.30$ & 2.328 & 0.067 \\
\hline E7×GZW006 & $59.77 \pm 2.38$ & & \\
\hline $\mathrm{E} 1 \times \mathrm{GZW} 054$ & $95.54 \pm 1.37$ & 0.679 & 0.546 \\
\hline E7×GZW054 & $94.05 \pm 1.77$ & & \\
\hline $\mathrm{E} 1 \times \mathrm{GZW} 054$ & $95.54 \pm 1.37$ & -0.464 & 0.688 \\
\hline $\mathrm{E} 8 \times \mathrm{GZW} 054$ & $96.81 \pm 0.08$ & & \\
\hline E1×GZW099 & $89.28 \pm 1.07$ & 6.34 & 0.001 \\
\hline E7×GZW099 & $77.79 \pm 0.56$ & & \\
\hline $\mathrm{E} 1 \times \mathrm{GZW} 013$ & $74.95 \pm 3.69$ & 0.215 & 0.837 \\
\hline $\mathrm{E} 8 \times \mathrm{GZW} 013$ & $73.41 \pm 4.88$ & & \\
\hline E1×GZW094 & 89.85 & 37.564 & 0.017 \\
\hline E7×GZW094 & $69.03 \pm 0.32$ & & \\
\hline E1×GZW094 & 89.85 & 69.125 & 0.009 \\
\hline E8 $\times$ GZW094 & $50.34 \pm 0.33$ & & \\
\hline $\mathrm{E} 1 \times \mathrm{GZW} 133$ & $87.79 \pm 2.87$ & 3.749 & 0.020 \\
\hline E7 $\times$ GZW133 & $70.75 \pm 2.42$ & & \\
\hline $\mathrm{E} 1 \times \mathrm{GZW} 133$ & $87.79 \pm 2.87$ & 3.851 & 0.031 \\
\hline $\mathrm{E} 8 \times \mathrm{GZW} 133$ & 63.09 & & \\
\hline
\end{tabular}

\section{Molecular marker and pollen fertility analysis in paired $\mathbf{F}_{2}$}

Pollen fertility of each $F_{2}$ plant of three crosses $(E 1 \times$ GZW054, E7 $\times$ GZW054 and E8 $\times$ GZW054) was observed and the results are as follows (Figure 2, 3):

A total of $119 \mathrm{~F}_{2}$ individuals were checked of E $1 \times \mathrm{GZW} 054$. The maximum, minimum and average pollen fertility was $97.76,0.29$ and $87.36 \%$, respectively (Figure 2 ). A total of 115 plants showed normal pollen fertility $(>50 \%)$, and it constituted $96.64 \%$ of the total population.



Figure 2. Frequency distribution of pollen fertility in 119 individuals of $\mathrm{E} 1 \times \mathrm{GZW} 054$ in $\mathrm{F}_{2}$ population. 


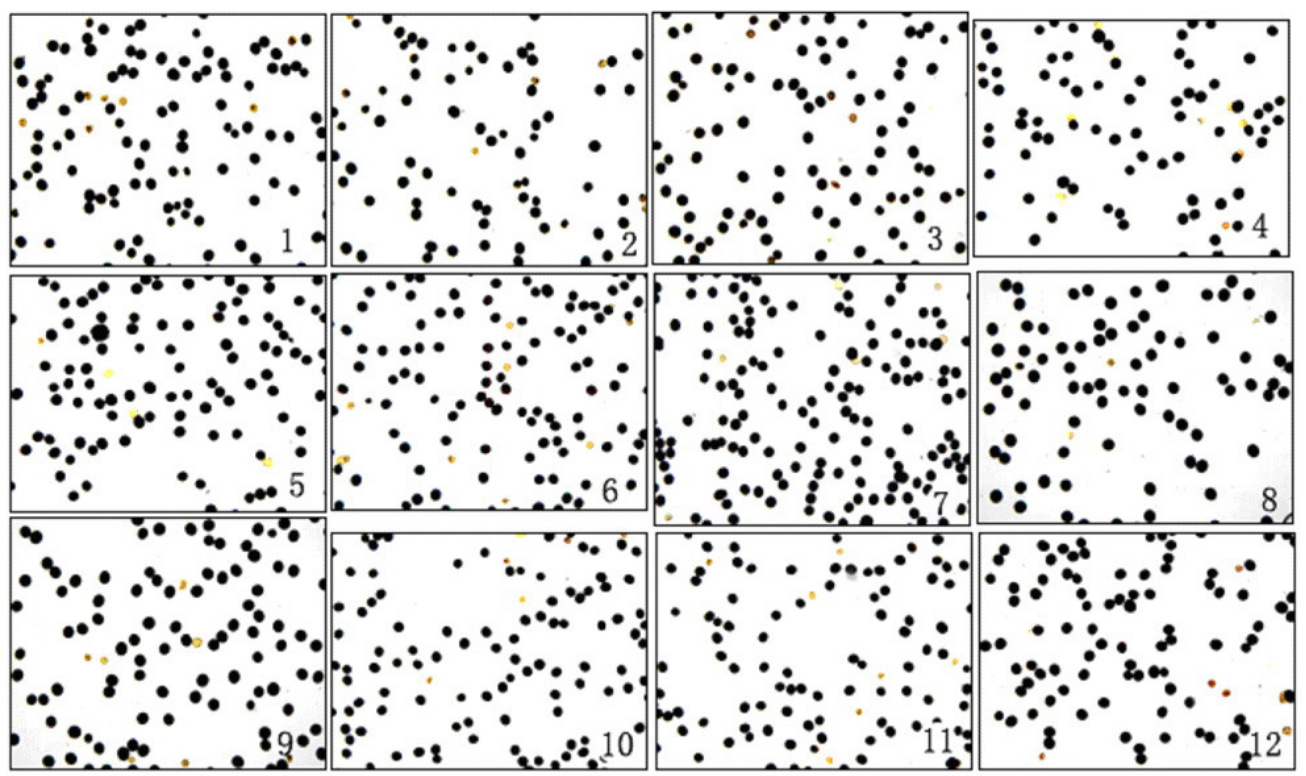

Figure 3. Pollen fertility of different genotypes in $\mathrm{F}_{2} \mathrm{~s}$ of $\mathrm{E}_{1}, \mathrm{E}_{7}, \mathrm{E}_{8}$ and GZW054. 1. $\mathrm{F}_{2}$ of $\mathrm{E}_{1} \times \mathrm{GZW} 054$ (genotype $S_{d}^{j} S_{d}^{j}$ ); 2. $\mathrm{F}_{2}$ of $\mathrm{E}_{1} \times \mathrm{GZW054}$ (genotype $S_{d}^{j} S_{d}^{n}$ ); 3. $\mathrm{F}_{2}$ of $\mathrm{E}_{1} \times \mathrm{GZW054}$ (genotype $S_{d}{ }^{2} S_{d}{ }^{n}$ ); $4 . \mathrm{F}_{2}$ of $\mathrm{E}_{7} \times \mathrm{GZW} 054$ (genotype $S_{d}^{2} S_{d}^{i}$ ); $5 . \mathrm{F}_{2}$ of $\mathrm{E}_{7} \times \mathrm{GZW054}\left(\right.$ genotype $S_{d}^{i} S_{d}^{n}$ ); 6. $\mathrm{F}_{2}$ of $\mathrm{E}_{7} \times \mathrm{GZW054}$ (genotype $S_{d}^{n} S_{d}{ }^{n}$ ); $7 . \mathrm{F}_{2}$ of $\mathrm{E}_{1} \times \mathrm{GZW} 054$ (genotype $S_{e}^{j} S_{e}^{j}$ ); 8. $\mathrm{F}_{2}$ of $\mathrm{E}_{1} \times \mathrm{GZW054}\left(\right.$ genotype $S_{e}^{j} S_{e}^{n}$ ); 9. $\mathrm{F}_{2}$ of $\mathrm{E}_{1} \times \mathrm{GZW} 054$ (genotype $S_{e}^{n}$ $S_{e}{ }^{n}$ ); 10. $\mathrm{F}_{2}$ of $\mathrm{E}_{8} \times \mathrm{GZW} 054$ (genotype $S_{e}^{i} S_{e}^{i}$ ); 11. $\mathrm{F}_{2}$ of $\mathrm{E}_{8} \times \mathrm{GZW054}\left(\right.$ genotype $S_{e}^{i} S_{e}{ }^{n}$ ); 12. $\mathrm{F}_{2}$ of $\mathrm{E}_{8} \times \mathrm{GZW} 05^{e}$ (genotype $S_{e}^{n} S_{e}^{n}$ ).

Similarly, the average pollen fertility of E7 $\times$ GZW054 in $\mathrm{F}_{2}$ generation was $86.40 \%$ (Table 2), and it ranged from 2 to $100 \%$ in 174 samples, and a total of 166 plants showed normal pollen fertility $(>50 \%)$, and it accounted for $95.40 \%$ of the total population.

Table 2. Genotypic distribution of the molecular markers and their corresponding pollen fertility in the $\mathrm{F}_{2}$ populations of E1 $\times$ GZW054 and E7 $\times$ GZW054.

\begin{tabular}{|c|c|c|c|c|c|c|c|c|}
\hline \multirow[t]{2}{*}{ Testcross } & \multirow[t]{2}{*}{$\begin{array}{l}\text { Molecular } \\
\text { makers }\end{array}$} & \multirow[t]{2}{*}{ Genotypes } & \multirow[t]{2}{*}{ Number of plant } & \multirow[t]{2}{*}{$\begin{array}{l}\text { Pollen fertility } \\
(\%)(\text { mean } \pm \text { SE })\end{array}$} & \multicolumn{2}{|c|}{$\begin{array}{l}\text { Chi-squared test for } \\
\text { genotypes }\end{array}$} & \multicolumn{2}{|c|}{$\begin{array}{l}\text { Analysis of variance } \\
\text { for pollen fertility }\end{array}$} \\
\hline & & & & & $\overline{\chi^{2} \text { value }}$ & $\overline{P \text { value }}$ & $\overline{\text { F value }}$ & $P$ value \\
\hline \multirow[t]{6}{*}{ E1×GZW054 } & \multirow[t]{3}{*}{ PSM13 } & $1\left(S_{d}^{j} S_{d}^{j}\right)$ & 34 & $90.58 \pm 1.06$ & \multirow[t]{3}{*}{0.078} & \multirow[t]{3}{*}{0.962} & \multirow[t]{3}{*}{0.847} & \multirow[t]{3}{*}{0.432} \\
\hline & & $2\left(S_{d}^{j} S_{d}^{d}\right)$ & 72 & $87.51 \pm 2.12$ & & & & \\
\hline & & $3\left(S_{d}^{n} S_{d}^{n}\right)$ & 35 & $84.81 \pm 4.52$ & & & & \\
\hline & \multirow[t]{3}{*}{ PSM91 } & $1\left(S_{d}^{j} S_{d}^{j}\right)$ & 32 & $90.48 \pm 1.63$ & \multirow[t]{3}{*}{2.751} & \multirow[t]{3}{*}{0.349} & \multirow[t]{3}{*}{2.751} & \multirow[t]{3}{*}{0.068} \\
\hline & & $2\left(S_{d}^{j} S_{d}^{d}\right)$ & 86 & $88.37 \pm 1.73$ & & & & \\
\hline & & $3\left(S_{d}^{n} S_{d}^{n}\right)$ & 38 & $81.21 \pm 4.55$ & & & & \\
\hline \multirow[t]{9}{*}{ E7×GZW054 } & \multirow[t]{3}{*}{ PSM41 } & $1\left(S_{d}^{i} S_{d}^{d i}\right)$ & 55 & $87.94 \pm 2.45$ & \multirow[t]{3}{*}{2.941} & \multirow[t]{3}{*}{0.230} & \multirow[t]{3}{*}{0.381} & \multirow[t]{3}{*}{0.893} \\
\hline & & $2\left(S_{d}^{i} S_{d}^{n}\right)$ & 89 & $87.29 \pm 1.89$ & & & & \\
\hline & & $3\left(S_{d}^{n} S_{d}^{n}\right)$ & 58 & $83.80 \pm 3.00$ & & & & \\
\hline & \multirow[t]{3}{*}{ PSM42 } & $1\left(S_{d}^{i}{ }^{i} S_{d}^{d}\right)$ & 37 & $83.15 \pm 5.18$ & \multirow[t]{3}{*}{5.856} & \multirow[t]{3}{*}{0.054} & \multirow[t]{3}{*}{0.645} & \multirow[t]{3}{*}{0.526} \\
\hline & & $2\left(S_{d}^{i} S_{d}^{d}\right)$ & 103 & $87.50 \pm 1.43$ & & & & \\
\hline & & $3\left(S_{d}^{n}{ }^{n} S_{d}^{n}\right)$ & 61 & $86.50 \pm 2.39$ & & & & \\
\hline & \multirow[t]{3}{*}{ PSM43 } & $1\left(S_{d}^{i} S_{d}^{i}\right)$ & 59 & $83.00 \pm 3.31$ & \multirow[t]{3}{*}{2.682} & \multirow[t]{3}{*}{0.262} & \multirow[t]{3}{*}{1.527} & \multirow[t]{3}{*}{0.220} \\
\hline & & $2\left(S_{d}^{d} S_{d}^{d}\right)$ & 90 & $87.15 \pm 1.71$ & & & & \\
\hline & & $3\left(S_{d}^{n} S_{d}^{d}\right)$ & 52 & $89.14 \pm 1.91$ & & & & \\
\hline
\end{tabular}


A total of 106 plants of E8 $\times$ GZW054 were observed and their average pollen fertility was $82.36 \%$ (Table 3 ). The minimum and maximum pollen fertility was 4.4 and $98.79 \%$, respectively. A total of 99 plants showed normal pollen fertility ( $>50 \%)$, and it was $93.40 \%$ of the population.

\begin{tabular}{|c|c|c|c|c|c|c|c|c|}
\hline \multirow[t]{2}{*}{ Testcross } & \multirow[t]{2}{*}{$\begin{array}{l}\text { Molecular } \\
\text { makers }\end{array}$} & \multirow[t]{2}{*}{ Genotypes } & \multirow[t]{2}{*}{ Number of plant } & \multirow[t]{2}{*}{$\begin{array}{l}\text { Pollen fertility } \\
(\%)(\text { mean } \pm \text { SE) }\end{array}$} & \multicolumn{2}{|c|}{$\begin{array}{l}\text { Chi-squared test for } \\
\text { genotypes }\end{array}$} & \multicolumn{2}{|c|}{$\begin{array}{l}\text { Analysis of variance } \\
\text { for pollen fertility }\end{array}$} \\
\hline & & & & & $\chi^{2}$ value & P value & F value & $P$ value \\
\hline \multirow[t]{2}{*}{ E1×GZW054 } & PSM597 & $\begin{array}{l}1\left(S_{e}^{j} S_{e j}^{j}\right) \\
2\left(S_{e}^{j} S_{e}^{n}\right) \\
3\left(S_{e}^{n} S_{e}^{n}\right)\end{array}$ & $\begin{array}{l}37 \\
70 \\
44\end{array}$ & $\begin{array}{l}88.86 \pm 2.06 \\
86.97 \pm 2.37 \\
86.13 \pm 3.02\end{array}$ & 1.450 & 0.484 & 0.239 & 0.788 \\
\hline & PSM448 & $\begin{array}{l}1\left(S_{e}^{j} S_{e}^{j}\right) \\
2\left(S_{e}^{j} S_{e}^{n}\right) \\
3\left(S^{n} S^{n}\right)\end{array}$ & $\begin{array}{l}43 \\
82 \\
30\end{array}$ & $\begin{array}{l}89.72 \pm 1.82 \\
87.38 \pm 1.94 \\
83.14 \pm 4.85\end{array}$ & 2.703 & 0.259 & 1.104 & 0.335 \\
\hline \multirow[t]{2}{*}{ E8×GZW054 } & PSM461 & $\begin{array}{l}3\left(S_{e}{ }^{i} S_{e}{ }^{i}\right) \\
2\left(S_{e}{ }^{i}{ }_{e} S_{e}{ }^{n}{ }^{n}\right. \\
3\left(S_{e} S_{e} S_{e}^{n}\right)\end{array}$ & $\begin{array}{l}30 \\
38 \\
56 \\
26\end{array}$ & $\begin{array}{l}83.14 \pm 4.85 \\
87.17 \pm 2.63 \\
82.68 \pm 2.32 \\
78.89 \pm 3.91\end{array}$ & 2.000 & 0.368 & 1.756 & 0.178 \\
\hline & PSM559 & $\begin{array}{l}1\left(S_{e}^{i} S_{e}^{i}\right) \\
2\left(S_{e}^{i} S_{e}{ }^{n}\right) \\
3\left(S^{n} S^{n}\right)\end{array}$ & $\begin{array}{l}31 \\
62 \\
32\end{array}$ & $\begin{array}{l}80.81 \pm 4.88 \\
82.84 \pm 2.29 \\
82.42 \pm 2.77\end{array}$ & 0.024 & 0.988 & 0.107 & 0.898 \\
\hline
\end{tabular}

The highly polymorphic molecular markers between E1 and GZW054, i.e. PSM13 and PSM91 at $S d$ locus were selected. The distribution of three genotypes (maternal, parental, and heterozygous) in their $\mathrm{F}_{2}$ is shown in Figure 4, Figure 5 and Table 2. The segregation ratio of the three genotypes for both markers in the $\mathrm{F}_{2}$ population followed the expected Mendelian ratio (1:2:1) based on the chi-squared test results ( $\mathrm{P}=0.962$ and 0.349 , respectively), and average pollen fertility corresponding to the three genotypes in the $\mathrm{F}_{2}$ population showed non-significant difference based on the analysis of variance $(\mathrm{P}=0.432$ and 0.068 , respectively). Therefore, it indicated that the alleles of GZW054 had no interaction with those of E1 at $S d$ locus.

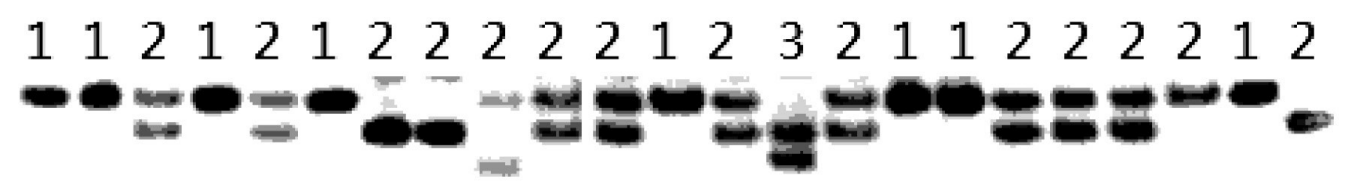

Figure 4. Genotypes of PSM13 in the $\mathrm{F}_{2}$ population of E1 $\times$ GZW054. 1-3 indicate maternal genotype (E1), heterozygous genotype and paternal genotype (GZW054) in $\mathrm{F}_{2}$ population, respectively.

\section{$\begin{array}{llllllllllllllllllllllll}2 & 2 & 1 & 3 & 2 & 2 & 3 & 2 & 3 & 1 & 3 & 2 & 3 & 2 & 2 & 1 & 2 & 2 & 1 & 2 & 1 & 2 & 2\end{array}$

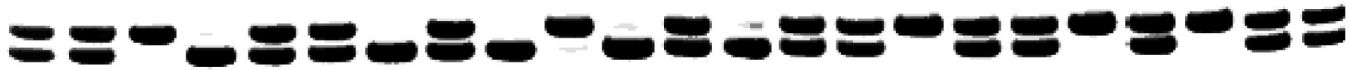

Figure 5. Genotypes of PSM91 in the $\mathrm{F}_{2}$ population of E1 $\times$ GZW054. 1-3 indicate maternal genotype (E1), heterozygous genotype and paternal genotype (GZW054) in $\mathrm{F}_{2}$ population, respectively.

Furthermore, the SSR markers PSM41, PSM42 and PSM448 were selected for tracing the genotypic distribution in the $\mathrm{F}_{2}$ of E7 $\times$ GZW054 because of high polymorphism be- 
tween them. It showed that the distribution of the three genotypes in the $F_{2}$ of E7 $\times$ GZW054 fitted the Mendelian ratio of 1:2:1 using a chi-squared test $(\mathrm{P}=0.230,0.054$ and 0.262 , respectively), and there were non-significant difference in average pollen fertility corresponding to the three genotypes based on the analysis of variance $(\mathrm{P}=0.893,0.526$ and 0.220 , respectively) (Table 2). It suggested that there was no interaction between the alleles of E7 and GZW054 at $S d$ locus.

According to the method of identifying neutral alleles, it was confirmed from the above results that the alleles of GZW054 are compatible to those of E1 (i.e. $S S^{\prime}$ ) and E7 (i.e. $S i S^{i}$ ) at $S d$ locus and thus, we concluded that GZW054 has a neutral gene at $S d$ locus (i.e. $S_{d}{ }^{n} S_{d}^{n}$ ).

Similarly, the molecular markers PSM597 and PSM448 were highly polymorphic between E1 $\times$ GZW054 as well as PSM461 and PSM559 for E8 $\times$ GZW054 at Se locus. We obtained similar results to $S d$ locus, i.e. the segregation ratio of the three genotypes in their $\mathrm{F}_{2}$ population fitted the expected Mendelian ratio (1:2:1) (Table 3) based on a chi-squared test, and the average pollen fertility corresponding to the three genotypes in their $\mathrm{F}_{2}$ population showed non-significant difference by the analysis of variance for both crosses (Table 3 ). Therefore, the results indicted that GZW054 has a neutral gene at Se locus.

\section{DISCUSSION}

Hybrid sterility is common between the subspecies of rice. On one hand, it drives speciation and evolution; on the other hand, it blocks favorable genes/traits intercross as combining elite genes/traits together in breeding is needed. Wide Compatibility Gene theory (Ikehashi and Araki, 1984) and Specific Compatibility Hypothesis (Zhang and Lu, 1989, 1993) was used to overcome the embryo sac sterility and pollen sterility, respectively. It can increase spikelets fertility of indica-japonica hybrids by introducing neutral genes into subspecies. It is well known that wide-compatibility gene $S_{5}{ }^{n}$ proposed by Ikehashi and Araki (1984), offered a bright prospect to overcome the sterility in indica-japonica hybrids. Recently, a compatibility gene $S_{a}^{n}$ for pollen sterility was proposed by Long et al. (2008). The rapid development of molecular marker techniques and genome sequencing has made it easier to identify neutral genes. A total of 10 wild rice accessions were identified carrying $S_{5}^{n}$ allele by functional molecular markers (Yang et al., 2009). However, sometimes molecular markers are not related to the gene, so phenotype identification by testcross is also necessary to obtain accurate results. Shi et al. (2009) proposed a new method to identify neutral genes by use of testcross and molecular markers together. This is an accurate method to identify neutral alleles and was applied in the present study.

Wild rice (O. rufipogon) is considered as an ancestor of cultivated rice and has a number of useful genes. Wild rice is resistant to pests and diseases, it can grow well in poor soil even in polluted water and it has many useful genes to improve rice varieties. Some earlier studies indicated that there might be neutral gene in wild rice. For example, high intra-specific hybrid fertility was found when wild rice was crossed with cultivated rice (Oka, 1964). There is a highly significant correlation between pollen fertility and spikelets fertility of the $F_{1} s$ between wild rice and cultivated rice, and wild rice has affinity with cultivated rice ( $\mathrm{Li}$ et al., 2007). Gaozhou wild rice has abundant genetic diversity and high pollen fertility ( $>85 \%)$ which was achieved when crossed with other cultivars (Lian et al., 2008). These results indi- 
cated that wild rice might have neutral genes for pollen fertility, which can overcome the pollen sterility of intra-specific hybrids. The present study furthermore confirmed that Gaozhou wild rice had neutral alleles for pollen fertility at $S d$ and $S e$ locus.

In our case, we used Taichung 65, a typical japonica cultivar and its NILs for pollen sterility locus as testers and combine traditional method (testcross) and molecular marker analysis together to detect neutral gene in wild rice. The materials used for testers were bred using Taichung 65 as a recipient parent and indica variety Dee-geowoo-gen, Guangluai-4 as donor parent through successive backcrossing ( $\mathrm{Li}$ et al., 2003, 2008; Zhu et al., 2008). Molecular markers were used to check the polymorphism between Taichung 65 and NILs and similar genetic background was found between them except at $S d$ and $S e$ loci (Li et al., 2008). Therefore, the results of present study are more precise than a common variety used as tester.

The pollen fertility of $F_{1}$ hybrid depends on allelic interaction at each pollen sterility locus. The neutral alleles did not have an interaction with both $S^{i}$ and $S^{i}$ alleles. Therefore, neutral alleles at each locus have potential to overcome the $F_{1}$ pollen sterility associated with the locus. Exploitation and utilization of neutral alleles are of significant importance. At present, $S_{a}^{n}$ was proposed by Long et al. (2008), $S_{b}{ }^{n}$ was detected by Shi et al. (2009), and $S_{d}^{n}$ and $S_{e}^{n}$ were found by our study. By pyramiding these novel neutral genes into elite cultivated rice varieties, varieties having strong compatibility either with indica or japonica would be expected. Thus, it provides an effective way and important germplasm to overcome the hybrid pollen sterility of $F_{1}$ between indica and japonica and enhance the utilization of the strong heterosis between subspecies.

\section{ACKNOWLEDGMENTS}

Research supported by the Joint Funds of the National Natural Science Foundation of China and Guangdong Province (Grant \#U0631003) and Natural Science Foundation of Guangdong Province (Grant \#5300831).

\section{REFERENCES}

Chen J, Ding J, Ouyang Y, Du H, et al. (2008). A triallelic system of $S_{5}$ is a major regulator of the reproductive barrier and compatibility of indica-japonica hybrids in rice. Proc. Natl. Acad. Sci. U. S. A. 105: 11436-11441.

Ding XH, Zhang ZM, Zeng RZ and Li WT (2003). Genotypic identification of Sb locus in the indica-compatible japonica lines of rice (Oryza sativa). Chin. J. Rice Sci. 17: 297-301.

Ikehashi $\mathrm{H}$ and Araki H (1984). Varietal screening for compatibility types revealed in $\mathrm{F}_{1}$ fertility of distant crosses in rice. Jpn. J. Breed. 34: 304-312.

Kato S (1930). On the affinity of the cultivated rice varieties of rice plants, Oryza sativa L. J. Depart. Agr. Kyushu Imp. Univ. 2: 241-275.

Li JQ, Lu YG, Feng JH and Zhao XJ (2007). The crossability and $\mathrm{F}_{1}$ hybrid fertility between Oryza sativa and other AA genome species. J. Plant Genet. Res. 8: 1-6.

Li WT, Zeng RZ, Zhang ZM and Zhang GQ (2003). Analysis of introgressed segments in near-isogenic lines for $\mathrm{F}_{1}$ pollen sterility in rice (Oryza sativa). Chin. J. Rice Sci. 17: 95-99.

Li WT, Zeng RZ, Zhang ZM, Ding XH, et al. (2006). Fine mapping of locus $S$ - $b$ for $\mathrm{F}_{1}$ pollen sterility in rice (Oryza sativa L.). Chin. Sci. Bull. 51: 404-408.

Li WT, Zeng RZ, Zhang ZM, Ding XH, et al. (2008). Identification and fine mapping of $S$ - $d$, a new locus conferring the partial pollen sterility of intersubspecific $\mathrm{F}_{1}$ hybrids in rice (Oryza sativa L.). Theor. Appl. Genet. 116: 915-922.

Lian ZX, Shi LG, Lu YG and Fu XL (2008). Pollen fertility and its developmental characteristics of the $\mathrm{F}_{1}$ between Oryza rufipogon Griff. indigenous to Gaozhou, Guangdong Province and Japonica rice. J. Plant Genet. Resour. 9: 6-10.

Liu HY, Xu CG and Zhang Q (2004). Male and female gamete abortions, and reduced affinity between the uniting gametes 
as the causes for sterility in an indica/japonica hybrid in rice. Sex. Plant Rep. 17: 55-62.

Long Y, Zhao L, Niu B, Su J, et al. (2008). Hybrid male sterility in rice controlled by interaction between divergent alleles of two adjacent genes. Proc. Natl. Acad. Sci. U. S. A. 105: 18871-18876.

Oka HI (1964). Consideration on the Genetic Basis of Intervarietal Sterility in Oryza sativa. In: Rice Genetics and Cytogenetics, International Rice Research Institute, 158-174.

Shahid MQ, Sun JF, Wei CM and Zhang P (2010). Studies on the abnormality of embryo sac and pollen fertility in autotetraploid rice during different growing seasons. Pak. J. Bot. 42: 7-19.

Shi LG, Liu XD, Liu B and Zhao XJ (2009). Identifying neutral allele $S b$ at pollen-sterility loci in cultivated rice with Oryza rufipogon origin. Chin. Sci. Bull. 54: 1-9.

Song X, Qiu SQ, Xu CG, Li XH, et al. (2005). Genetic dissection of embryo sac fertility, pollen fertility, and their contributions to spikelet fertility of intersubspecific hybrids in rice. Theor. Appl. Genet. 110: 205-211.

Wan JM and Ikehashi H (1997). Identification of two types of differentiation in cultivated rice (Oryza sativa L.) detected by polymorphism of isozymes and hybrid sterility. Euphytica $94: 151-161$.

Yang CY, Chen ZZ, Zhuang CX and Mei MT (2004). Genetic map and fine physical mapping of the gene $S$-c for $\mathrm{F}_{1}$ pollen sterility in cultivated rice (Oryza sativa L.). Chin. Sci. Bull. 49: 1273-1277.

Yang YX, Wu JW, Chen ZX and Wang L (2009). Mining rice new germplasm containing $S_{5}{ }^{n}$ gene by functional molecular marker and sequencing. Chin. Sci. Bull. 54: 3258-3264.

Yi CD, Yan CJ, Liang GH, Zhu LH, et al. (2001). RFLP analysis of the effect of wide compatibility genes in Aus variety 'Dular'. Yi Chuan Xue Bao 28: 540-549.

Yokoo M (1984). Female sterility in an indica-japonica cross of rice. Jpn. J. Breed. 34: 219-227.

Yuan LP (1987). Strategic hypotheses of breeding for hybrid rice. Hybrid Rice 1: 1-3.

Zhang GQ and Lu YG (1989). Genetic studies of the hybrid sterility in cultivated rice (Oryza sativa). I. Diallel analysis of the hybrid sterility among isogenic $\mathrm{F}_{1}$ sterile lines. Chin. J. Rice Sci. 3: 97-101.

Zhang GQ and Lu YG (1993). Genetic studies of the hybrid sterility in cultivated rice (Oryza sativa). II. A genic model for $F_{1}$ pollen sterility. Acta Genet. Sin. 20: 222-228.

Zhang GQ, Lu YG, Liu GF and Yang JC (1993). Genetic studies of the hybrid sterility in cultivated rice (Oryza sativa). III. Allele differentiation of $\mathrm{F}_{1}$ pollen sterility in different types of varieties. Acta Genet. Sin. 20: 541-551.

Zhang ZS, Lu YG, Liu XD, Feng JH, et al. (2006). Cytological mechanism of pollen abortion resulting from allelic interaction of $\mathrm{F}_{1}$ pollen sterility locus in rice (Oryza sativa L.). Genetica 127: 295-302.

Zheng KL, Huang N, Bennett J and Khush GS (1995). PCR-based phylogenetic analysis of wide compatibility varieties in Oryza sativa L. Theor. Appl. Genet. 88: 65-69.

Zhu WY, Li WT, Ding XH and Zhang ZM (2008). Preliminary identification of $\mathrm{F}_{1}$ pollen sterility gene S-e in Oryza sativa. J. South China Agr. Univ. 1: 1-5. 